\title{
PERBANDINGAN TEKNIK PEMERIKSAAN CARPAL CANAL PROYEKSI TANGENSIAL DENGAN METODE GAYNORT-HART INFEROSUPERIOR DAN CARPAL CANAL SUPEROINFERIOR UNTUK MENDAPATKAN GAMBARAN OS PSIFORM
}

\author{
Santa Mareta $^{1^{*}}$, Maulani Rahayu ${ }^{2}$ \\ ${ }^{1,2}$ Program Studi DIII Radiologi, Fakultas Vokasi, Universitas Baiturrahmah, Padang \\ Email:santamareta3@gmail.com
}

\begin{abstract}
ABSTRAK
Carpal Canal merupakan cekungan yang dibentuk oleh bagian palmar dari metacarpal. Dalam memperoleh gambaran Os pisiform tersebut ada beberapa proyeksi pemeriksaan yang sering dilakukan, salah satunya adalah carpal canal proyeksi tangensial metode gaynort-hart inferosuperior dan carpal canal superoinferior. Penelitian ini bertujuan untuk mengetahui metode mana yang lebih bagus untuk melihat Os Psiform. Penelitian dilakukan di Unit Radiologi RSU Aisyiyah Padang bulan September 2019. Metode yang digunakan adalah kuantitatif dengan studi eksperimen, hasil dari radiograf ini dibacakan oleh lima orang responden, data diolah menggunakan rumus Mean Score dan Statistical Product Service Solution (SPSS) dengan Uji Wilcoxon. Hasil penelitian untuk gambaran Os Psiform yang bebas superposisi nilai rata-rata pada metode inferosuperior adalah 3,56 dan pada metode superoinferior adalah 2,64. Sedangkan menggunakan SPSS didapatkan dengan nilai signifikannya 0,039 ( $p$ value $<0,05$ ) maka $\mathrm{H}_{0}$ ditolak dan $\mathrm{H}_{\mathrm{a}}$ diterima, yang berarti ada perbedaan yang signifikan dari kedua metode.
\end{abstract}

Kata kunci: os psiform, metode inferosuperior, metode superoinferior

\section{ABSTRACT}

Carpal Canal is a basin created by Palmar from Metacarpal. One of several revenue projections made, one of which is the carpal canal. The tangential method is the inferosuperior gaynor-hart method and the superoinferior carpal canal. This research is to learn which method is better to see Os Psiform. The study was conducted at the Radiology Unit of Aisyiyah Public Hospital Padang in September 2019. The method used was quantitative with experimental studies, the results of this radiograph were read out by five respondents, data were processed using the Mean Score and Statistical Product Service Solution (SPSS) formula with the Wilcoxon Test. The results of the study for the description of Os Psiform free of superposition the average value in the inferosuperior method was 3.56 and in the superoinferior method was 2.64. While using SPSS obtained with a significant value of 0.039 ( $p$ value $<0.05$ ) then $\mathrm{HO}$ is rejected and $\mathrm{Ha}$ is accepted, which means there are significant differences from the two methods. 
Keywords: os psiform, inferosuperior method, superoinferior method

\section{PENDAHULUAN}

Tulang psiform disebut juga dengan pisiformis atau lentiform, adalah tulang kecil menonjol, berbentuk kacang pergelangan tangan (Doyle \& Botte, 2003). Tulang psiform adalah tulang terluar dari pergelangan tangan dan terletak dibawah jari kelingking ditangan. Ada dua proyeksi yang digunakan untuk memperlihatkan gambaran os psiform yaitu proyeksi carpal canal inferosuperior dan carpal canal superoinferior dengan posisi duduk di samping meja pemeriksaan dengan arah sinar proyeksi inferosuperior $25-30^{\circ}$ caudall dan proyeksi superoinferior dengan arah sinar vertikal (Ballinger, 1995).

Pada pemeriksaan wrist joint didapatkan bahwa os psiform mengalami superposisi sehingga tidak dapat menegakkan diagnosa (Rahman, 2009). Berdasarkan latar belakang tersebut, peneliti tertarik untuk melakukan penelitian lebih dalam mengenai perbandingan teknik pemeriksaan carpal canal proyeksi tangensial metode gaynort-hart inferosuperior dan carpal canal superoinferior untuk mendapatkan gambaran os psiform. Sehingga anatomi os Psiform terlihat optimal dan baik sehingga dapat menegakkan diagnosa oleh dokter.

Adapun tujuan dari penelitian ini untuk mengetahui anatomi carpal canal proyeksi tangensial metode gaynort-hart inferosuperior dan carpal canal superoinferior dan untuk mengetahui proyeksi manakah yang memperlihatkan os psiform yang optimal.

\section{METODOLOGI PENELITIAN}

Penelitian ini dilakukan di Instalasi Radiologi Rumah Sakit Umum Aisyiyah Padang. Dilakukan pada bulan September 2019. Jenis penelitian kuantitatif dengan studi eksperimen. Dengan sampel 5 orang pasien yang melakukan pemeriksaan Wrist Joint.

\section{HASIL DAN PEMBAHASAN}

Setelah dilakukan penelitian terhadap 5 orang pasien dengan menggunakan teknik pemeriksaan carpal canal proyeksi tangensial metode gaynort-hart inferosuperior dan carpal canal superoinferior untuk mendapatkan gambaran os psiform, maka di dapatkan perbandingan hasil radiograf pemeriksaan wrist joint seperti gambar dibawah ini.
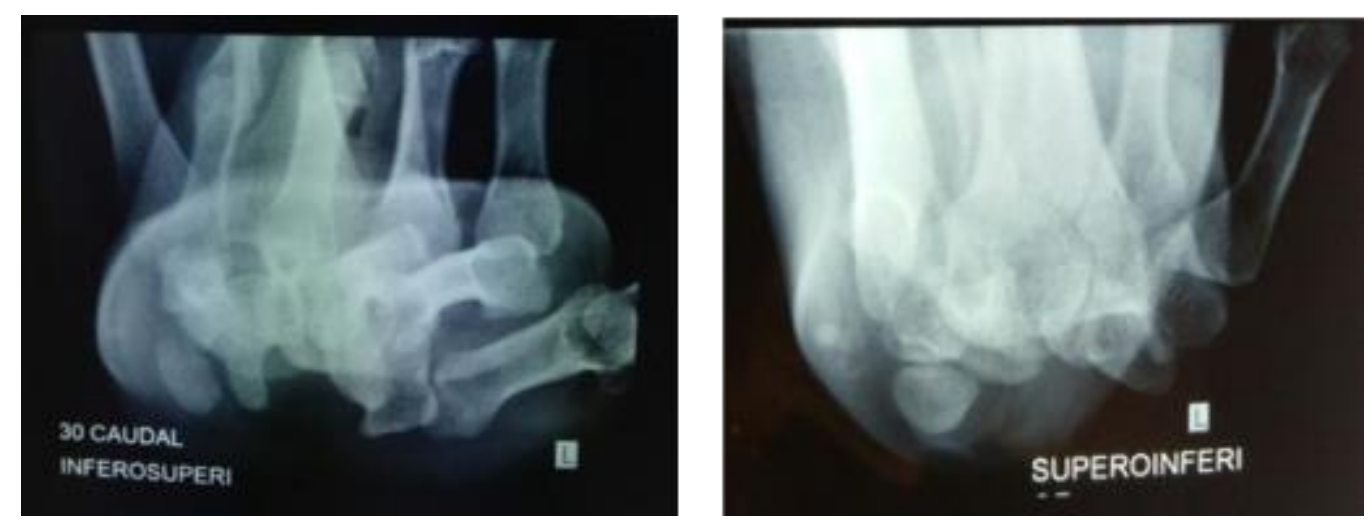

Gambar 1. Hasil radiograf pemeriksaan wrist joint pasien 1 (Ny. S)/L 

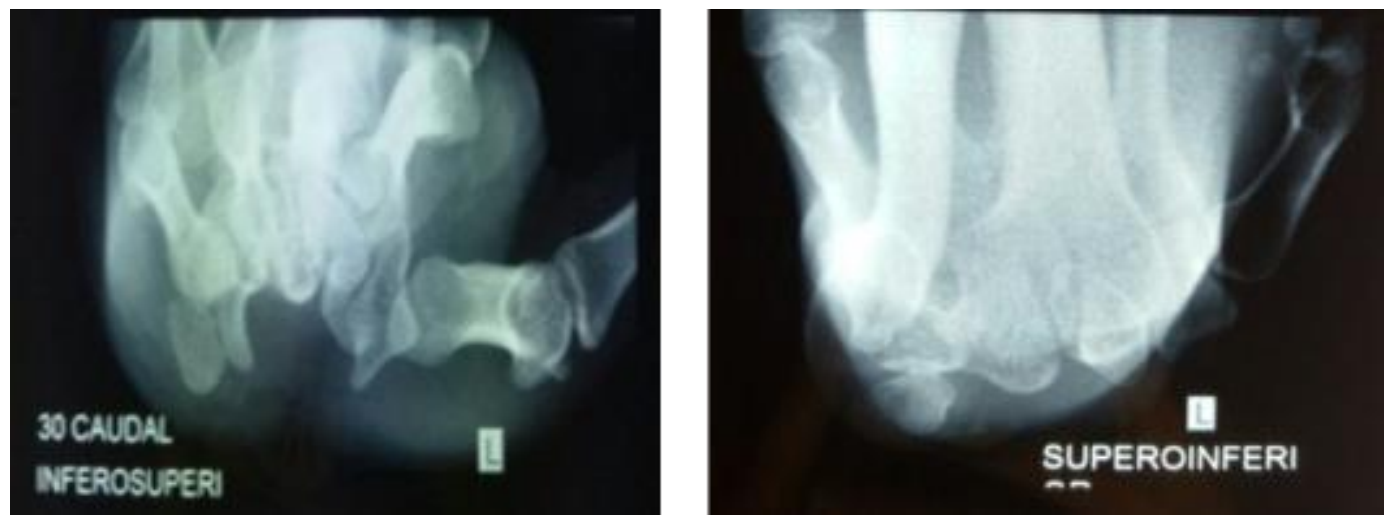

Gambar 2. Hasil radiograf pemeriksaan wrist joint pasien $2(\mathrm{Nn} . \mathrm{H}) / \mathrm{L}$
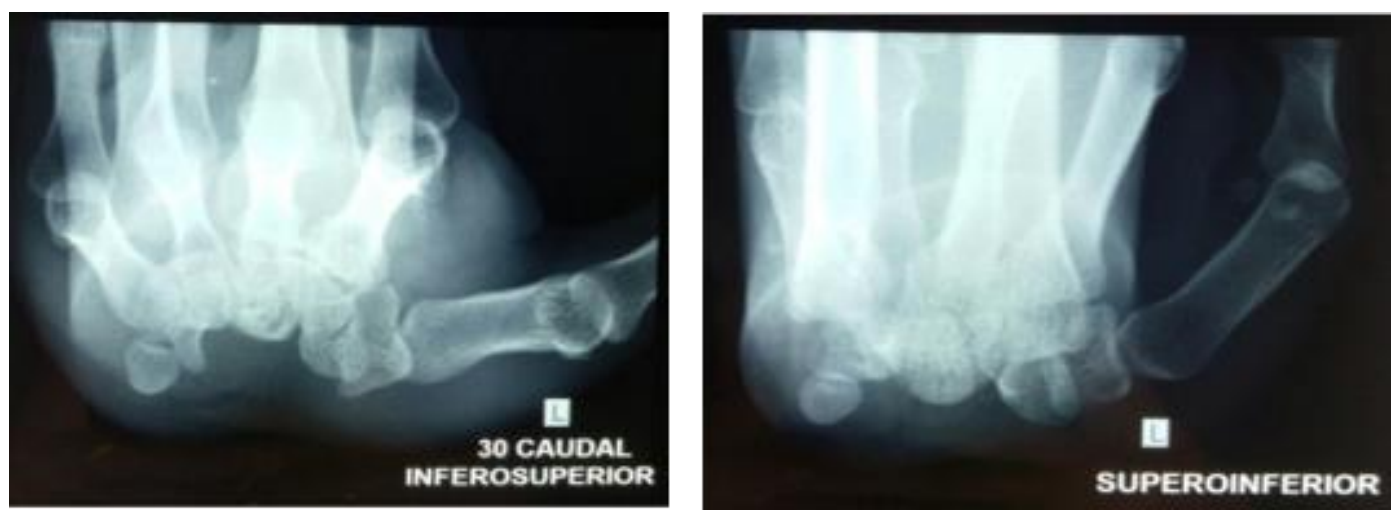

Gambar 3. Hasil radiograf pemeriksaan wrist joint pasien 3 (Ny. I)/L
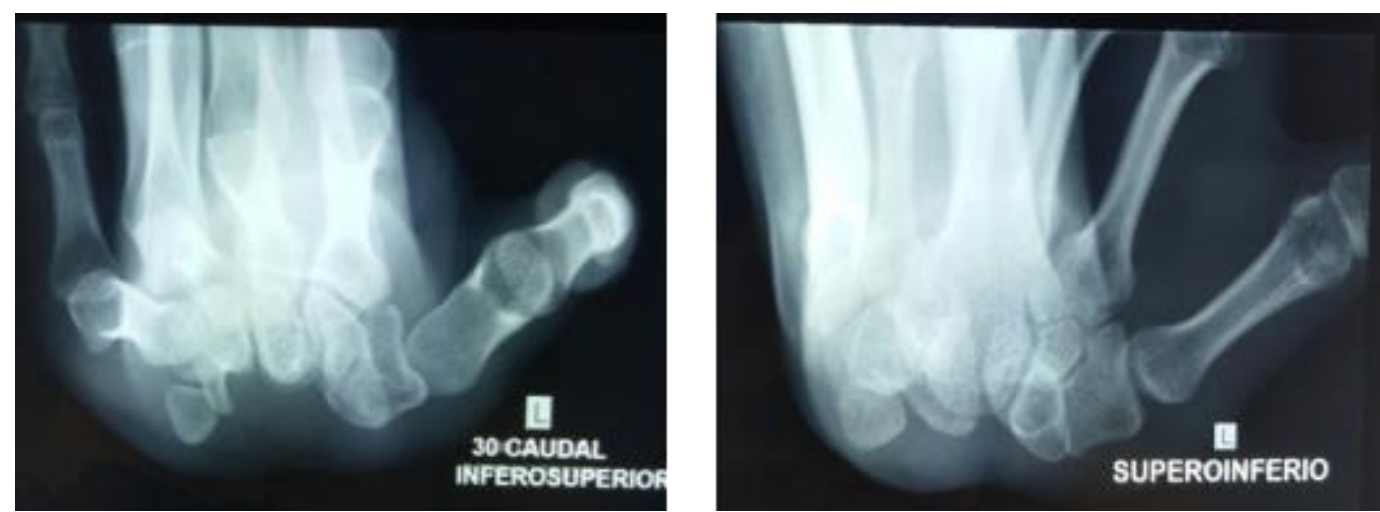

Gambar 4. Hasil radiograf pemeriksaan wrist joint pasien 4 (Ny. Y)/L 

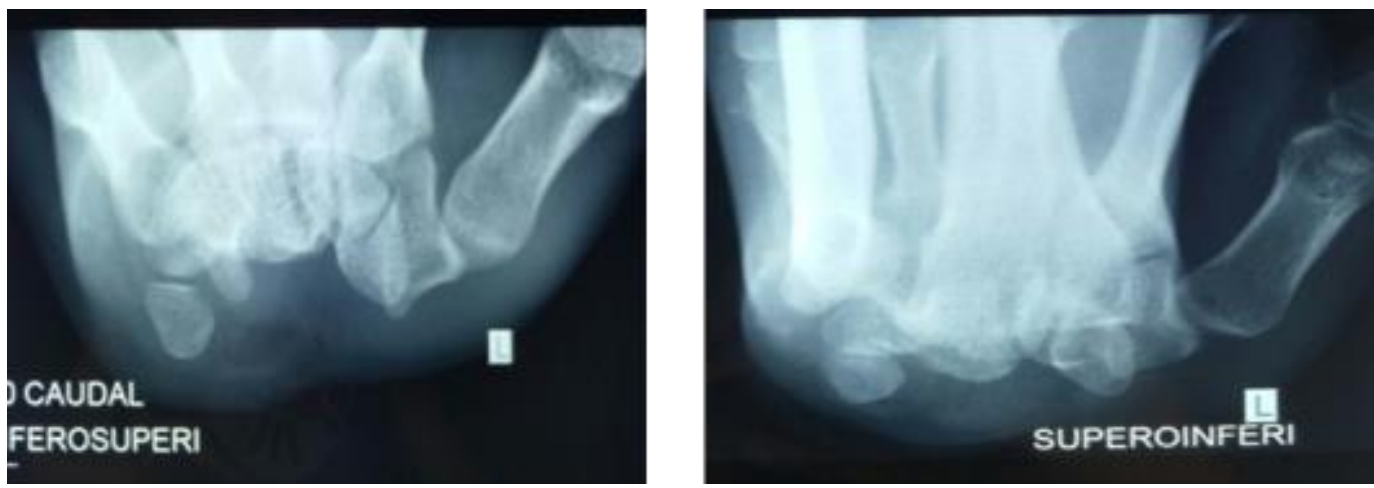

Gambar 5. Hasil radiograf pemeriksaan wrist joint pasien 5 (Ny. E)/L

Setelah melakukan penelitian perbandingan carpal canal untuk mendapatkan gambaran os psiform dengan menggunakan proyeksi tangensial metode gaynort-hart inferosuperior dan superoinferior dilanjutkan dengan pengambilan lembaran kuesioner oleh lima orang dokter Radiologi. Maka nilai yang didapatkan dari hasil penelitian berupa kumpulan data kuesioner oleh responden.

Tabel 1. Hasil kuisioner dokter radiologi terhadap radiograf pasien 1 (Ny. S)/L

\begin{tabular}{cccc}
\hline Pertanyaan & Responden & Inferosuperior & Superoinferior \\
\hline & 1 & 4 & 3 \\
Gambaran $O s$ Psiform manakah yang bebas & 2 & 4 & 4 \\
superposisi? & 3 & 4 & 3 \\
& 4 & 4 & 4 \\
\hline Jumlah & 5 & 4 & 3 \\
\hline$\overline{\boldsymbol{x}}$ & & $\mathbf{2 0}$ & $\mathbf{1 7}$ \\
\hline
\end{tabular}

Tabel 2. Hasil kuisioner dokter radiologi terhadap radiograf pasien 2 (Nn. H)/L

\begin{tabular}{cccc}
\hline Pertanyaan & Responden & Inferosuperior & Superoinferior \\
\hline & 1 & 3 & 2 \\
Gambaran Os Psiform manakah yang bebas & 2 & 4 & 2 \\
superposisi? & 3 & 4 & 3 \\
& 4 & 3 & 3 \\
\hline Jumlah & 5 & 2 & 3 \\
\hline$\overline{\boldsymbol{x}}$ & & $\mathbf{1 6}$ & $\mathbf{1 3}$ \\
\hline
\end{tabular}

Tabel 3. Hasil kuisioner dokter radiologi terhadap radiograf pasien 3 (Ny. I)/L

\begin{tabular}{cccc}
\hline Pertanyaan & Responden & Inferosuperior & Superoinferior \\
\hline & 1 & 3 & 2 \\
Gambaran Os Psiform manakah yang bebas & 2 & 4 & 3 \\
superposisi? & 3 & 3 & 2 \\
& 4 & 4 & 3 \\
\hline Jumlah & 5 & 3 & 1 \\
\hline$\overline{\boldsymbol{x}}$ & & $\mathbf{1 7}$ & $\mathbf{1 1}$ \\
\hline
\end{tabular}

Tabel 4. Hasil kuisioner dokter radiologi terhadap radiograf pasien 4 (Ny. Y)/L

\begin{tabular}{cccc}
\hline Pertanyaan & Responden & Inferosuperior & Superoinferior \\
\hline & 1 & 4 & 3 \\
Gambaran Os Psiform manakah yang bebas & 2 & 4 & 2 \\
superposisi? & 3 & 3 & 3 \\
& 4 & 3 & 2 \\
& 5 & 2 & 3
\end{tabular}




\begin{tabular}{cccc}
\hline Jumlah & 16 & 13 \\
\hline $\bar{x}$ & 3,2 & 2,6 \\
\hline
\end{tabular}

Tabel 5. Hasil kuisioner dokter radiologi terhadap radiograf pasien 5 (Ny. E)/L

\begin{tabular}{cccc}
\hline Pertanyaan & Responden & Inferosuperior & Superoinferior \\
\hline & 1 & 4 & 2 \\
Gambaran Os Psiform manakah yang bebas & 2 & 4 & 3 \\
superposisi? & 3 & 4 & 3 \\
& 4 & 4 & 2 \\
\hline Jumlah & 5 & 4 & 2 \\
\hline$\overline{\boldsymbol{x}}$ & & $\mathbf{2 0}$ & $\mathbf{1 2}$ \\
\hline
\end{tabular}

Berdasarkan hasil penelitian perbandingan hasil radiograf carpal canal inferosuperior dan carpal canal superoinferior terhadap lima orang pasien dan hasil radiograf tersebut dibacakan oleh lima responden yaitu lima Dokter Spesialis Radiologi dengan mendapatkan hasil yang bervariasi, dan dapat dirangkum sebagaimana tabel berikut.

Tabel 6. Hasil kuisioner dokter radiologi terhadap radiograf seluruh pasien

\begin{tabular}{ccc}
\hline Pertanyaan & $\begin{array}{c}\text { Proyeksi } \\
\text { Inferosuperior }\end{array}$ & $\begin{array}{c}\text { Proyeksi } \\
\text { Superoinferior }\end{array}$ \\
\hline $\begin{array}{c}\text { Gambaran Os Psiform manakah yang bebas } \\
\text { superposisi? }\end{array}$ & $\mathbf{3 , 5 6}$ & $\mathbf{2 , 6 4}$ \\
\hline
\end{tabular}

Pada pemeriksaan dengan menggunakan proyeksi Inferosuperior, posisi objek dengan pergelangan lengan bawah menempel pada kaset. Untuk menghindari gambaran yang berhimpit dari tulang hamatum dan psiform, maka tangan sedikit dirotasikan ke arah radial. Tangan yang tidak diperiksa menarik tangan yang diperiksa semampu pasien dengan central point 1 inchi $(2,5 \mathrm{~cm})$ distal dari dasar metacarpal ke-3 central ray $25-30^{\circ}$ ke caudall (Ballinger, 1995). Hasil pengolahan data dari kuisioner yang dilakukan terhadap lima orang responden yang merupakan dokter spesialis radiologi, menunjukkan gambaran os psiform memperoleh nilai mean (rata-rata) sebesar 3,56, dengan nilai minimum 3,2 dan nilai maksimum 4,0, serta standar deviasi (simpang baku) sebesar 0,4099. Sehingga didapatkan hasil tampak anatomi os psiform tidak superposisi dengan os triquertum dengan sangat jelas. Sedangkan pada pemeriksaan dengan menggunakan proyeksi superoinferior, posisi objek jari-jari yang menempel pada kaset dan menggunakan spons dengan sudut $45^{\circ}$ di bawah permukaan telapak tangan sehingga sedikit mengangkat pergelangan tangan untuk meningkatkan objek ke image distance (OID) (Ballinger, 1995). Nilai mean (rata-rata) yang diperoleh dari pengolahan data kuisioner adalah sebesar 2,64, dengan nilai minimum 2,2, nilai maksimum 3,4, serta standar deviasi (simpang baku) sebesar 0,4561. Sehingga didapatkan hasil tampak anatomi os psiform sedikit superposisi dengan os triquertum.

Berdasarkan hasil uji tes statistik dari data tersebut dapat menyatakan bahwa nilai signifikasi yang diperoleh dari perhitungan SPSS adalah sekitar 0,039 ( $p$ value < 0,05) (Notoatmodjo, 2012), sehingga $\mathrm{H}_{0}$ ditolak dan $\mathrm{H}_{\mathrm{a}}$ diterima. Hal ini menunjukkan bahwa ada perbedaan yang signifikan dalam melihat os psiform metode tangensial proyeksi gaynort-hart inferosuperior dan superoinferior. Dari hasil penelitian bahwa pemeriksaan carpal canal untuk mendapatkan os psiform diperoleh informasi bahwa antomi yang lebih unggul adalah proyeksi Inferosuperior dibandingkan proyeksi Superoinferior, karena gambaran os psiform bebas superposisi dengan os triquertum. 


\section{KESIMPULAN}

Nilai rata-rata yang diperoleh dari pemeriksaan carpal canal inferosuperior adalah sebesar 3,56, sedangkan pemeriksaan carpal canal superoinferior adalah sebesar 2,64. Dalam hal ini bisa dinyatakan bahwa dari kedua metode tersebut untuk mendapatkan informasi anatomi yang lebih informatif ini akan lebih baik menggunakan metode inferosuperior dibandingkan metode superoinferior, karena mengurangi gambaran os psiform yang superposisi. Hasil perhitungan menggunakan SPSS ( $P$ Value sebesar 0,039$)$ menunjukkan adanya perbedaan yang signifikan antara metode gaynort-hart inferosuperior dan superoinferior.

\section{UCAPAN TERIMA KASIH}

Penulis mengucapkan terimkasih banyak kepada Rumah Sakit Umum Aisyiyah Padang yang telah memberikan izin untuk melakukan penelitian.

\section{DAFTAR PUSTAKA}

Ballinger, P. W. (1995). Radiographic Positioning and Radiologic Procedures. United State: Louis Mosby Company.

Doyle, J. R., \& Botte, M. J. (2003). Surgical Anatomy of The Hand and Upper Extremity. China: Lippincott Williams \& Wilkins.

Notoatmodjo, S. (2012). Metodologi Penelittian Kesehatan. Jakarta: Rineka Cipta.

Rahman, N. (2009). Radiofotografi. Padang: Universitas Baiturrahmah. 